\title{
FAMILIAL DYSAUTONOMIA AS AN ANAESTHETIC HAZARD
}

\section{Thomas J. MCCAUGhiEY, M.B., B.CH."}

Familial dysautonomia, or the Riley-Day syndrome, is a rare disease but a peculiarly interesting one to the anaesthetist. Any patient who is capable of sudden gross variations in blood pressure presents us with something of a challenge. Add to this a tendency to severe hyperpyrexia with convulsions, fits of intractable vomiting, and recurrent pulmonary infections, and the cup begins to overflow. Indeed the only report in the literature based on sizeable experience is quite forbidding. ${ }^{1}$ The present paper deals with findings in anaesthetizing one of these patients for six major surgical procedures.

\section{Clinical Picture and Special Tests}

The disease is more extensive than the name suggests. Luckily, at least one of the symptoms, marked indifference to pain, is to our advantage. Other features, such as retardation of growth and mental development, emotional upsets, faulty speech, diminished tendon reflexes, and skin blotching are really of no concern to us here. They are only mentioned as odd pieces in a most puzzling pharmacological and physiological puzzle. But the findings related to the autonomic nervoús system are of intense interest to us. Fellner ${ }^{2}$ gives an excellent review of world-wide experience with the disease and the percentage occurrence of various symptoms and signs.

The syndrome was first properly described in $1949 .{ }^{3}$ The diagnosis rests essentially on clinical grounds. Any child who cries without tears; is given to emotional upsets, fevers, excessive sweating, and drooling; and whose parents are-Jewish (in about eight cases out of ten) can be presumed to have the disease. The presence of an unexplained and fluctuating hypertension makes familial dysautonomia almost a certainty.

The various special tests which have been described are neither entirely specific nor invariably present. Absence of flaring with histamine, ${ }^{4}$ though useful confirmation, is found in other diseases of the peripheral nerves, ${ }^{5}$ and sometimes in pheochromocytoma. ${ }^{6}$ Abnormal catecholamine metabolism, ${ }^{7}$ though of interest in considering the basic nature of the condition, is not allways found. ${ }^{5}$

\section{Case History}

Our patient gave us a unique opportunity to study the disease. Over a period of two years she underwent six major operations under general ${ }^{\circ}$ anaesthesia to correct scoliosis. None lasted less than two hours. After the first two anaesthetics

*Chief Anaesthetist, The Children's Hospital, Winnipeg, Manitoba; Assistant Professor of Surgery (Anaesthesia), University of Manitoba, Winnipeg, Manitoba. Presented at the Annual Meeting of the Canadian Anaesthetists' Society, Charlottetown, P.E.I., June 21-25, 1965. 
we had a good idea of what to expect, both during surgery and afterwards. An effort was then made to probe the effects of various techniques and agents in order to throw some light, if possible, on the basic nature of the disease. In the following narrative all the anaesthetics will be considered together as far as possible.

When first seen in May, 1963, the patient was almost nine years of age and weighed approximately $23 \mathrm{~kg}$. She was the youngest child of Jewish parents and presented" an unmistakable picture. She cried without tears, had bilateral corneal opacities and a labile hypertension, and very easily got attacks of hyperpyrexia and cyclic vomiting. The diagnosis had been made at two years of age. This is by no means a record; indeed, a suggestion was recently made that the condition could be picked up in the first 24 hours of life. ${ }^{8}$ Our patient had been admitted twice previously with convulsions and serious attacks of bronchopneumonia, and on one occasion she almost died. Diagnostic electroencephalograms had been done, showing a great deal of spiking activity. For one of these tests a resident had given intravenous thiopental. It is frustrating and humiliating to note that he did not take the blood pressure and thereby missed finding something very interesting.

\section{Pre-Anaesthetic Medication}

The patient was most apprehensive on all her voyages to the operating room. Neither complete familiarity nor fairly powerful sedlation could abate her terror. On the first four occasions she was given meperidine $1 \mathrm{mg} . / \mathrm{kg}$. and atropine $0.4 \mathrm{mg}$. preoperatively; on the fifth, chlorpromazine $1 \mathrm{mg} . \mathrm{kg}$. with atropine $0.4 \mathrm{mg}$, and on the sixth, chlorpromazine $1 \mathrm{mg} . / \mathrm{kg}$. with meperidine $1 \mathrm{mg} . / \mathrm{kg}$. On the last occasion she was quieter that ever before but would suddenly startle on being disturbed and cry out at her strange surroundings. She begged to be given a needle and. received intravenous thiopental and succinylcholine for all inductions.

\section{INDUCTION}

The doses of thiopental and the immediate falls in systolic blood pressure are shown in Figure 1. Some of them were quite abrupt. On no occasion did the pressure go below $80 \mathrm{~mm}$. Hg., and recovery was rapid if only nitrous oxide and oxygen were used to follow. There was no great cause for alarm, and the technique seemed quite justified in view of the child's perturbed state. One cannot accept the suggestion that intravenous thiopental is absolutely contraindicated. A slower induction with an inhalation agent would be preferable in the presence of other aggravating factors such as hypovolaemia from acute blood loss. The doses used were generous but administration was quite slow. On the last occasion (pre-anaesthetic medication with chlorpromazine and meperidine) the smallest dose was used. Here both preinjection level and subsequent fall were nearest to what would have been predicted in a normal child.

On no occasion was succinylcholine observed to have a prolonged effect. Since 


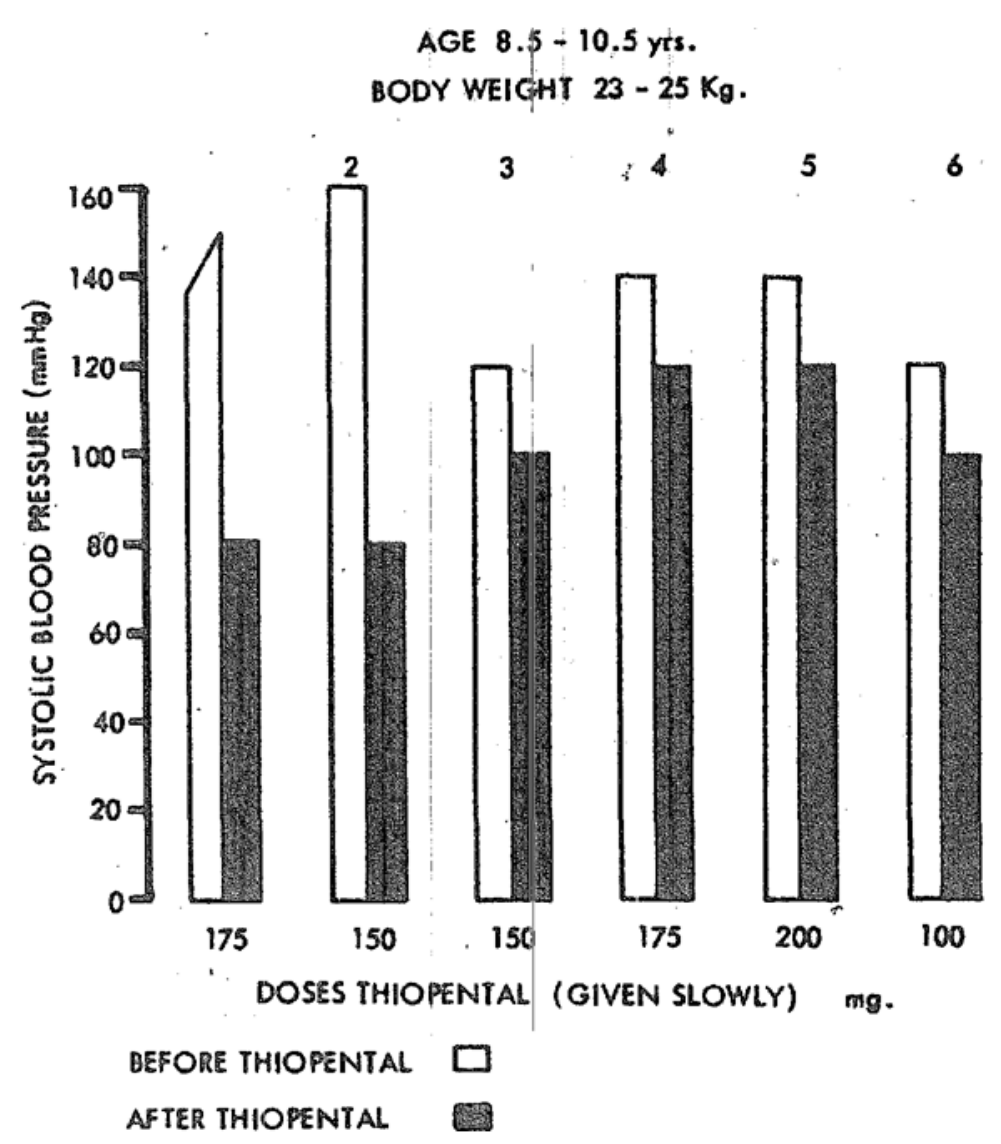

Figure 1. Effects on systolic blood pressure of thiopental induction or six separate occasions.

acetylcholine may play a major role in this condition, the action of succinylcholine is of some interest and should be investigated further.

\section{MaInTenance}

On the first occasion ( June 17, 1963), anaesthesia was maintained with hitrous oxide and oxygen at equal flow rates with minimal methoxyfluorane by means of a circle technique and controlled respiration using a Jefferson Ventilator. The patient was prone, for a Harrington spinal fusion.

Apart frøm two incidents about to be described, anaesthesia was quite uneventful. Blood pressure remained stable, if low, ranging from $80-85 \mathrm{~mm}$. Hg. systolic with a pulse rate of 70-80 per minute. When the skin incision was made, blood pressure and pulse rose at once to $108 \mathrm{~mm}$. $\mathrm{H}$ g. systolic and $110 / \mathrm{min}$. respectively. Slightly increased depth of anaesthesia obtained by means of methoxyflurane lowered pulse and blood pressure to basal levels again. Methọxyllurane was turned off for long periods of time and only given when muscular movement occurred.

The second incident was more serious. A sudden onset of hiccoughing disrupted control of respiration. When methoxyflurane was pushed in an effort to restore calm, the systolic blood pressure rapidly dropped to $55 \mathrm{~mm}$. $\mathrm{Hg}$. and complete heart-block was seen on the electrocardiograph. Methoxyflurane- was shut off and both blood pressure and electrocardiograph readings returned to their previous state.

An arterial blood sample was taken after $2^{1 / 4}$ hours of general anaesthesia and the blood gases were analysed, giving the results shown in Table I. 
TABLE I

After $2 \frac{1}{4}$ Hours' Controlled Respikation

\begin{tabular}{lc}
\hline $\mathrm{pH}$ & 7.43 \\
$p \mathrm{CO}_{2}$ & $35 \mathrm{~mm} . \mathrm{Hg}$. \\
Standard bicarbonate & $24 \mathrm{~m} \mathrm{Eq} . / \mathrm{L}$. \\
\hline
\end{tabular}

The consistently low arterial blood pressure suggested that the use of positive pressure breathing might be affecting cardiac output. Negative pressure was therefore incorporated in the expiratory phase $(+12,-10 \mathrm{~mm} . \mathrm{Hg}$. $)$ in an effort to lower the mean airway pressure. The blood pressure did not change.

A year later the child came up for removal of Hiarrington rods. This time, after induction with thiopental, only 70 per cent nitrous oxide with oxygen was used. A non-rebreathing technique (Stephen-Slater Valve) was employed, and the ease of control of respiration was remarkable. The very most was made of the marked absence of pain sensation. Systolic blood pressure varied between 90 and $100 \mathrm{~mm}$. Hg., and pulse rate between 64 and 70 per minute. This was altogether a smooth and easy anaesthetic.

We were confident that a predictable pattern had been safely establishedat least for intra-operative problems. Postoperative problems are dealt with later. There would be no great difficulty if anaesthesia were controlled with nitrous oxide and oxygen only. Subsequent operations were therefore used to explore and chart as precisely as possible the so-far unknown reactions to a number of techniques and agents.

On November 25, 1964, our patient came up for het third operation, a thoracolumbar spinal fusion which lasted almost three hours. Through most of the procedure she was allowed to breathe spontaneously, receiving nitrous oxide (75\%) and oxygen (25\%) by a non-rebreathing technique. Occasionally methoxyflurane (by Pentec vaporizer) was used to stop muscular movement, in concentrations between 0.1 and 0.5 per cent. It was rather easy in this way to depress blood pressure to $65 \mathrm{~mm}$. Hg. systolic, at which level neither electroencephalograph nor cardiograph readings gave any cause for concern.

It is interesting to note the effect of blood transfusion here (Fig. 2). When

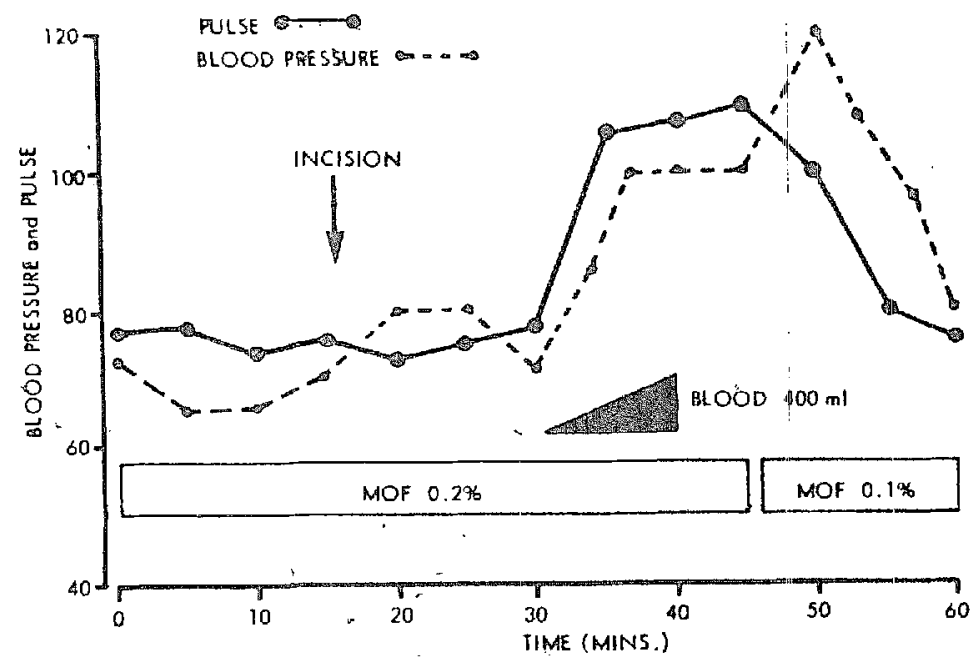

Figure 2. Effect of slight over-transfusion on pulse and blood pressure during methoxyflurane anaesthesia (MOF). 
the blood loss, measued by sponge weighing, was $278 \mathrm{ml}$, about $300 \mathrm{ml}$. of blood had been given. Transfusing up to a total of $400 \mathrm{ml}$. blood caused blood pressure and pulse to rise sharply. It was not thought that the patient was hypovolaemic, nor could the rise be related to light anaesthesia. The concentration of methoxyflurane being given at the time, 0.2 per cent, would usually have held the pressure down in this patient. Whatever the mechanism of the low blood pressure here, increasing the venous return certainly appeared to augment cardiac output promptly enough.

The arterial blood gases at the end of approximately two hours of spontaneous respiration on 75 per cent nitrous oxide and 25 per cent oxygen are shown in Table I.I. Although good evidence has been put forward to indicate that the respiratory centre in dysautonomic patients is rather insensitive to carbon dioxide, ${ }^{9}$ our findings do not support this.

TABLE II

Arterial Blood Gases after Two Hours' Spontaneous Respiration, 75 Per CênT $\mathrm{N}_{2} \mathrm{O}, 25$ PER Cent $\mathrm{O}_{2}$

\begin{tabular}{lc}
\hline $\mathrm{pH}$ & 7.34 \\
$\mathrm{pO}_{2}$ & $165 \mathrm{~mm} . \mathrm{Hg}$. \\
$\mathrm{pCO}_{2}$ & $46 \mathrm{~mm} . \mathrm{Hg}$. \\
Standard bicarbonate & $23.2 \mathrm{~m} . \mathrm{Eq} . / \mathrm{L}$. \\
\hline
\end{tabular}

The fourth occasion of major "surgery was for a further extension of the lumbar spinal fusion. During this operation, anaesthesia lasted about two hours. A nobn-rebreathing technique of spontaneous respiration was employed. Hạlothane and methoxyflurane were given by Fluotec and Pentec vaporizers. Two extra technicians were employed. One ran a permanent record of EKG and EEG. The other took down a minute-to-minute account of the findings of the anaesthetist and correlated it with the paper tracing. The results were carefully analyzed and are shown in Figure 3.

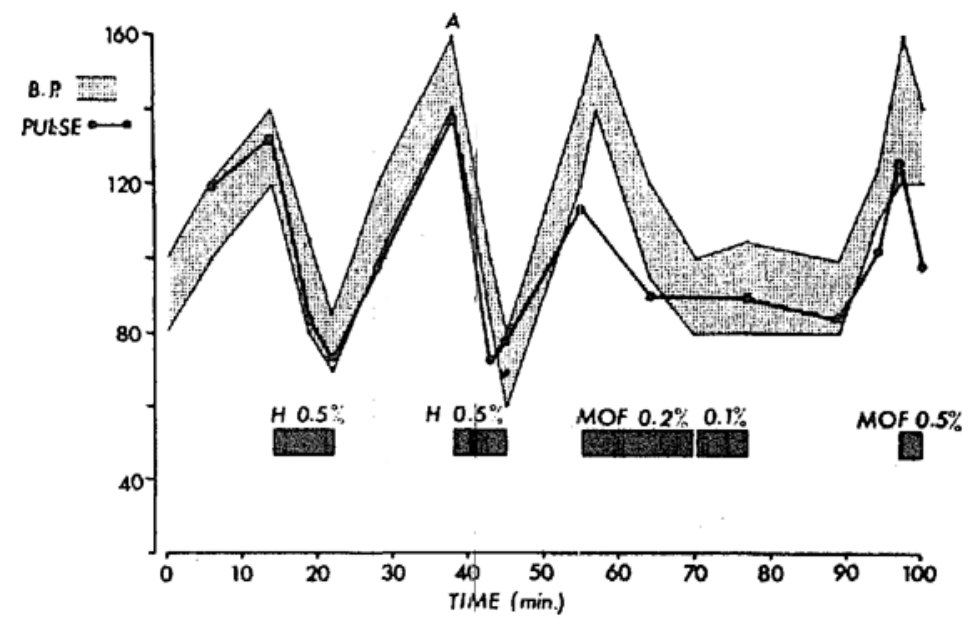

Figure 3. Spontaneous respiration-non-rebreathing. Note great instability of pulse and blood pressure with halothane $(\mathrm{H})$, less marked with methoxyflurane (MOF). A: see EEG and 'EKG in Figurè 4. 
The instability of blood pressure and pulse with halothane was extraordinary and would rule out this agent here. It is interesting that both diastolic blood pressure and pulse rate followed systolic pressure closely. By what mechanism is this achieved? It is certainly not typical of the usual response to epinephrine or norepinephrine alone. It could be caused by both together. The answer may lie partly in the fact that dysautonomic patients have an abnormal response to norepinephirine. There is an exaggerated blood-pressure rise and tachycardia. ${ }^{10}$ It was not unexpected that when the blood pressure reached $160 / 140 \mathrm{~mm}$. $\mathrm{Hg}^{*}$, sudden spiking activity should appear on the electroencêphalogräph (Fig. 4). What was somewhat surprising was that the EKG remained perfectly. normal throughout.
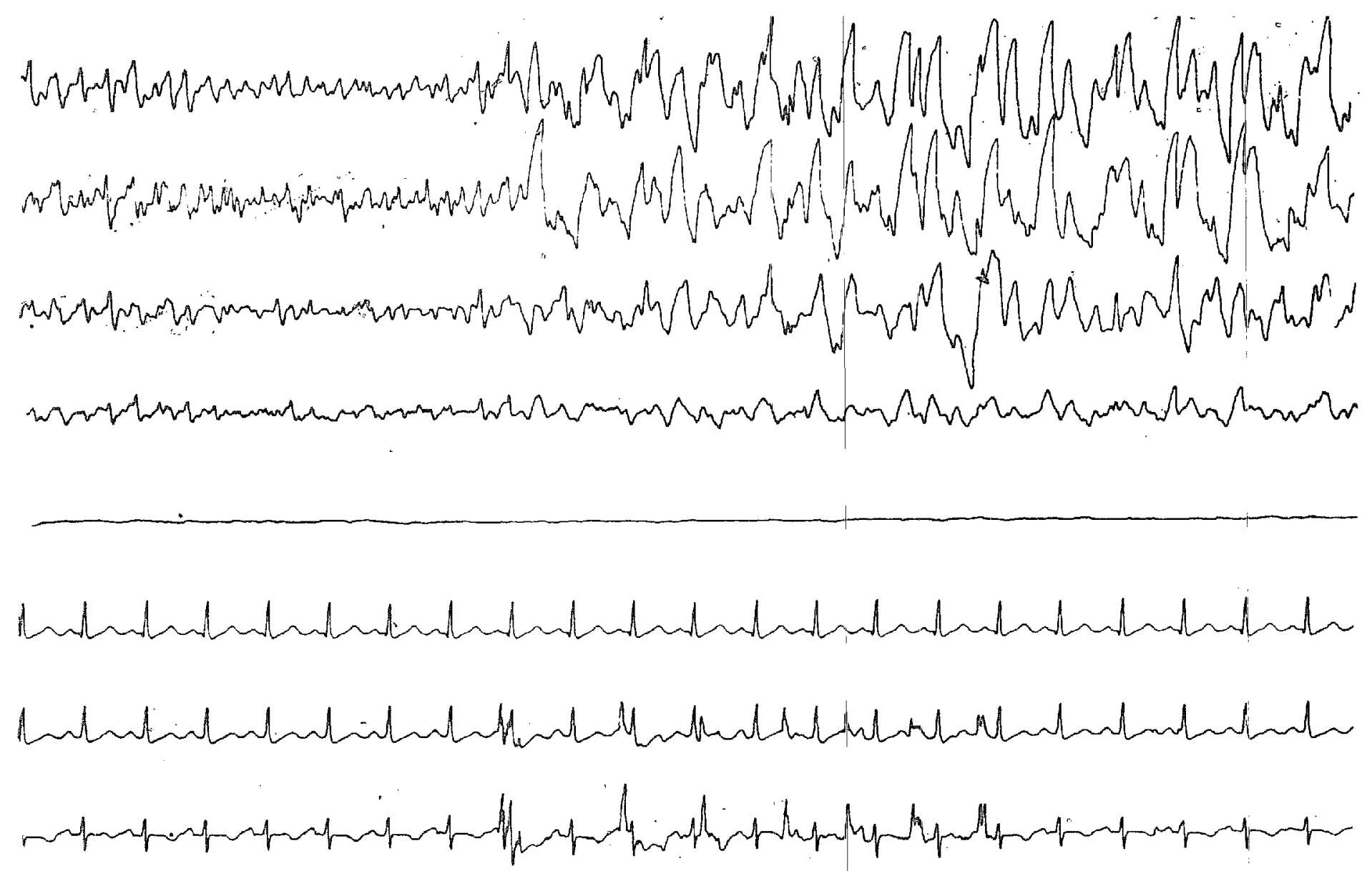

Figure 4. Note sudden change in EEG, none in EKG. Cf. point $\mathbb{A}$ in Figure 3.

Variations in pressure with methoxyflurane were less abrupt. That the agent could also cause severe hyptension was well shown at the time of the next anaesthetic (Fig. 5). On February 26, 1965, the child was placed in pelvic skeleton traction. The use of controlled respiration with Methoxyflurane caused a drop in blood pressure similar to the one that occurred during the first operation.

The sixth anaesthetic, on May 31, 1965, demonstrated that ether was also capable of hypotensive action (Fig. 6). The fall in both blood pressure and pulse mean that in dysautonomic patients ether does not produce its characteristic release of catecholamines. Only the depressant effect of the agent is to be seen. It is not possible to say with assurance whether this effect is caused by a central action on the nervous system or by an action on the heart, or by both. 


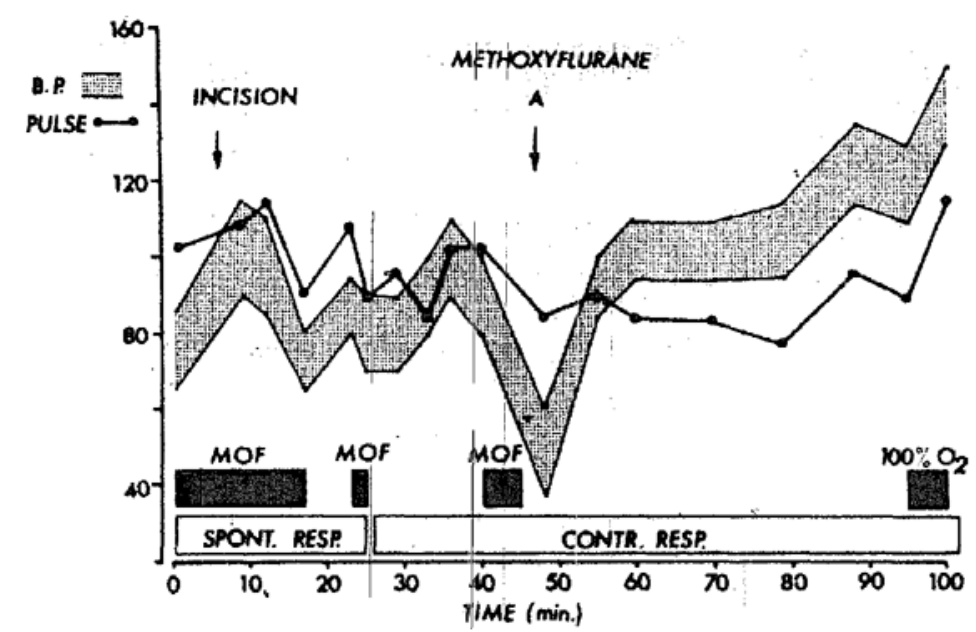

Figure 5. Spontaneous and controlled respiration using methoxyflurane (MOF). Note hypotensive potentiality of methoxyflurane at point A.

The evidence suggests that ether, and probably all the other inhalation agents, produce their lowering effect on blood pressure through a central action in these patients. It is true that on this particular occasion the patient had been pre-medicated with chlorpromazine and had received methoxyflurane earlier in the course

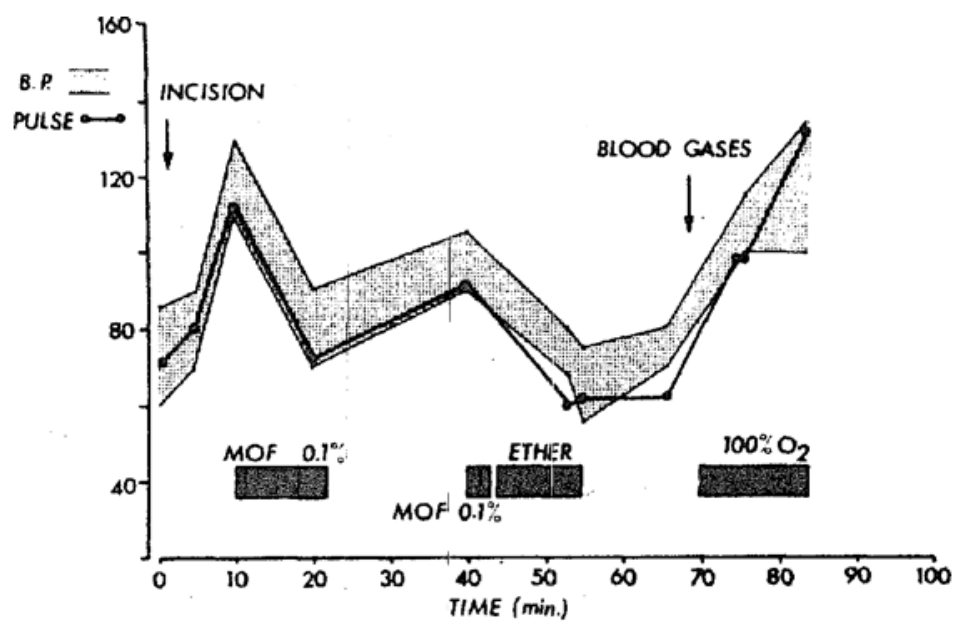

Figure 6. Spontaneous respiration-non-rebreathing, methoxyflurane (MOF) and ether. Note fall in blood pressure and pulse rate with ether. Arterial blood gases reported in text, see Table III.

of the same anaesthetic. Ether would still have been expected to produce some sympathetic effects in a normal patient.

The arterial blood gases after almost two hours of spontaneous respiration with nitrous oxide and oxygen (approximately 70\%:30\%) show once again that this patient had no abnormal tendency to accumulate carbon dioxide (Table III).

\section{Postoperative Complications}

Chlorpromazine proved to be a valuable agent in the control of postoperative complications, which were legion. The most consistent of these were persistent nausea and vomiting, gastric dilatation and ileus, hyperpyrexia, hypertension, and convulsions. The child had a marked tendency to postoperative infections and 
TABLE III

Arterial Blood Gases after ApproxiMately Two Hours' Spontaneous BrEathing OF Nitrous OXIDE (70) AND OXYGEN $(30 \%)$

\begin{tabular}{lc}
\hline \hline $\mathrm{pH}$ & 7.36 \\
$\mathrm{pO}_{2}$ & $130 \mathrm{~mm} . \mathrm{Hg}$. \\
$\mathrm{pCO}$. & $52 \mathrm{~mm} . \mathrm{Hg}$. \\
Standard bicarbonate & $25.1 \mathrm{~m} . \mathrm{Eq} / \mathrm{L}$. \\
Base excess & $+3.3 \mathrm{~m}$. Eq./L. \\
\hline
\end{tabular}

poor healing-not surprising in view of the peripheral neuropathy. On one occasion it was suspected that she was developing bacterial endocarditis; she had a positive blood culture, but fortunately endocarditis did not occur.

With increasing experience it was possible to simplify her treatment. Success varied inversely with the number of drugs employed. Barbiturates were not needed in the last postoperative course, much to the relief of her parents, who remarked that she was chronically depressed by them. No analgesics were necessary either, pain sensation being poorly developed. A combination of chlorpromazine and dimenhydrinate by intramuscular injection was very effective in controlling temperature, blood pressure, and nausea. The dose needed, $10 \mathrm{mg}$. of each, was smaller than one might have expected in a $25 \mathrm{~kg}$. patient. She was nursed on a water mattress through which cold water was circulated when her temperature rose to $101^{\circ} \mathrm{F}$. No originality is claimed for the use of chlorpromazine. It is an extremely useful drug for dysautonomic patients, as others have also found. ${ }^{1,11,12}$

Respiratory infections are very common in such patients. It is possible that aspiration of vomitus accounts for many occurrences, but in some patients an asthma-like condition is said to occur. ${ }^{11}$ Increased bronchial secretions can give rise to a condition rather like fibro-cystic disease. ${ }^{13}$

Dysautonomic patients exhibit very poor tolerance of hypoxia, compared with normal controls. Fainting, convulsions, and extreme cyanosis quickly appeared where normal individuals tolerated the same degree of hypoxia without great difficulty. ${ }^{9}$ These patients need careful watching postoperatively to forestall such occurrences. Intermittent positive pressure assistance to respiration with oxygen is advisable.

\section{What is the Nature of Familial Dysautonomia?}

The basic cause of dysautonomia remains unexplained. Neither gross nor microscopic pathology is usually present. Biopsy of the lacrimal glands has been reported as negative. ${ }^{11}$ Patients with a clinical picture resembling megacolon have been found to have normal ganglion cells in the bowel wall. ${ }^{2}$ There is a consensus of opinion that the disease may be due to some inherited enzymatic defect and that acetylcholine may play a major role. ${ }^{11,14}$ Burn and Rand ${ }^{15,16}$ have shown how acetylcholine may trigger the release of norepinephrine at certain sites, and have indicated that it may have two types of action on the same organ. Feldberg 
and Fleischauer ${ }^{17}$ have demonstrated, in somewhat artificial conditions in experimental animals, that norepinephrine, epinephrine, and serotonin can have direct effects on the thalamic nuclei which control heat conservation, heat loss, and shivering. There are interesting implications of this work in general anaesthesia as well as in familial dysautonomia. For example, there may be a connection here with the variability of temperature during general anaesthesia and with the puzzling phenomenon of post-anaesthetic spasticity and shivering.

The metabolism of epinephrine and norepinephrine is often abnormal in dysautonomics. Less of the ordinary end product, vanillylmandelic acid (VMA) and more of a break-down product of intermediary metabolism, homovanillic acid (HVA) are said to be typically excreted (Fig. 7). This reversal of the usual HVA:VMA ratio is not present in all cases.

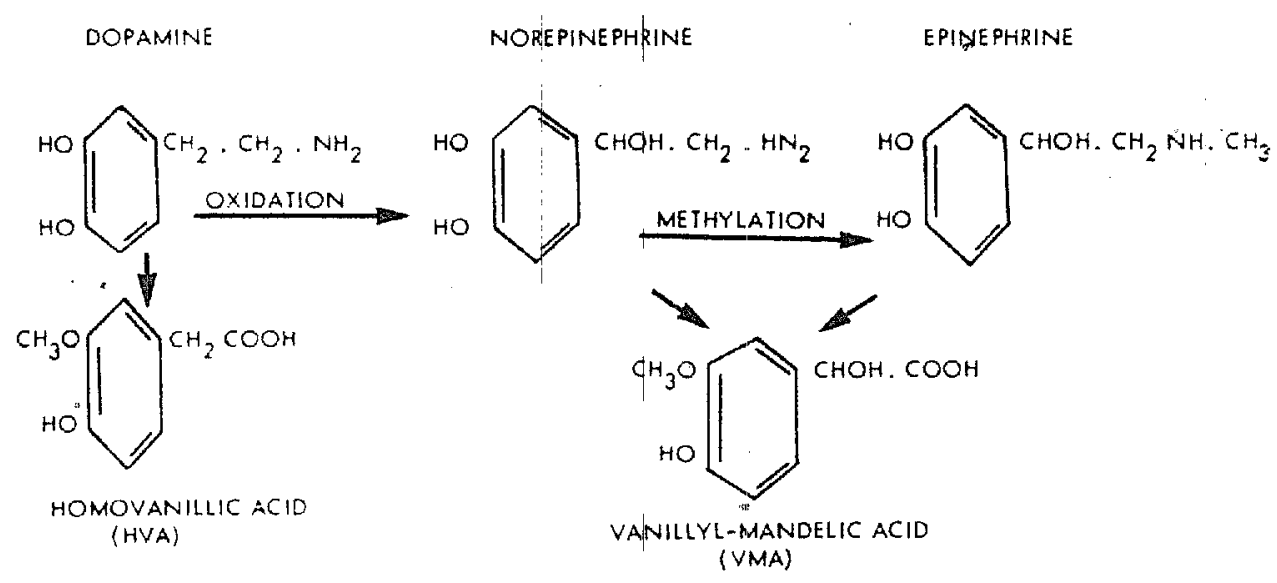

Figure 7. Catecholamine metabolism. VMA is ordinary endproduct of norepinephrine and epinephrine. HVA, an intermediary metabolite, is increased in familial dysautonomia while VMA is proportionately reduced.

The autonomic nervous system is frequently pictured and taught as an anatomical entity centred around the thoraco-lumbar outflow. Alternatively it is described from the point of view of the pharmacology of acetylcholine and the catecholamines. Both approaches are incomplete and unrealistic. The concept of levels in the nervous system is out-dated. ${ }^{18}$ The results of dissociating peripheral mechanisms from central control are very interestingly demonstrated in the mass reactions of the condition known as autonomic hyperreflexia following spinal cord injury in humans. ${ }^{19} \mathrm{We}$ are coming to realize the great importance of the reticular activating system ${ }^{20}$ and of the hypothalamus and thalamus in integrating the so-called voluntary and autonomic nervous systems.

The depressant effects of halothane, methoxyflurane, and ether in the case just reported could well have been centrally mediated through the reticular activating substance. It is quite possible that an idea of how the dysautonomic differs from the normal patient would in turn give a clue to the mode of action of inhalation anaesthetics on the nervous system. The converse, of course, is also true.

The anaesthetic management of dysautonomic patients is challenging, but not excessively difficult. Controlled respiration with nitrous oxide only is probably best. We found no sensitivity to single doses of succinylcholine, and we plan to 
use it intermittently if we should have occasion to do so in the future. The safe use of curare has also been reported..$^{21}$ If an inhalation agent is thought necessary, methoxyflurane seems - a fair enough choice. This is one condition in which a reliable percentage vaporizer, such as the Pentec, is absolutely necessary; less than 0.5 per cent concentration is usually quite adequate.

\section{SUMMARY}

Familial dysautonomia is described as presented in the literature and as it appeared in a young girl who required six anaesthetics for major surgical procedures. Intravenous thiopental was used for induction and invariably caused a fairly sharp drop in blood pressure. A technique of light anaesthesia with nitrous oxide and oxygen was quite satisfactory for: maintenance. Pain sensation is often poor and stronger analgesics are usually unnecessary. Methoxyflurane, halothane, and ether were used and their effects on pulse, blood pressure, EEG, $\mathrm{EKG}$, and blood gases measured. All these agents caused striking depression of blood pressure and pulse rate. Methoxyllurane maintained more stable conditions than did halothane.

Post-operative nausea, intestinal stasis, hyperpyrexia, unstable blood pressure, convulsions, and respiratory infections are common. Chlorpromazine proved most useful in controlling nausea, temperature, and blood pressure.

The nature of the disease remains unknown. No gross or microscopic pathology has been described. The evidence suggests an enzymatic defect affecting the function and site of action of acetylcholine. This manifests itself throughout the whole nervous system but may act particularly in the reticular activating substance and thalamic nuclei.

\section{RÉSUMÉ}

Dans ce travail, il est question de la dysautonomie familiale d'après ce qu'en dit la littérature médicale, et d'après ce qu'on a observé chez une jeune fille qui a dû subir six anesthésies pour des opérations majeures. On a pratiqué l'induction au thiopentone et à chaque occasion il s'ensuivit une chute assez brusque de la pression artérielle. Pour le maintien de la narcose, une technique d'anesthésie légère au protoxyde d'azote-oxygène a été très satisfaisante. Les réactions à la douleur sont généralement faibles chez ces malades, et il est inutile d'utiliser des analgésiques puissants. On a employé le méthoxyflurane, Thalothane et l'éther, et on a enregistré leurs effets sur le pouls, la pression artérielle, l'électro-encéphalogramme, l'électrocardiogramme et les gaz du sang. Tous ces agents anesthésiques ont provoqué une diminution sensible de la pression sanguine et de la vitesse du pouls. Les signes vitaux sont demeurés plus stables avec le méthoxyflurane qu'avec l'halothane.

Chez ces malades, on observe couramment des nausées post-opératoires, de la stase intestinale, de la fièvre, une pression sanguine instable, des convulsions et des infections respiratoires. La chlorpromazine s'est avérée la plus utile pour contrôler les nausées, la fièvre et la pression artérielle. 
La nature de la maladie est encore inconnue. On n'a décrit aucune pathologie macroscopique ou microscopique. Tout porte à croire qu'il s'agit d'un trouble enzymatique qui affecte la fonction et le lieu d'action de l'acétylcholine. Ceci se manifeste dans tout le système nerveux mais peut prédominer dans la substance active réticulée et dans les noyaux thalamiques.

\section{ACKNOWLEDGMENTS}

Deepest thanks are due to Mr. Tony Gibson and the Department of Graphic Arts, to Miss June Hodges and the Department of Electroencephalography, and to our never-failing secretary, Mrs. Edith Baird.

\section{REFERENCES}

1. Kritchman, M. M.; Schwartz, H.; \& Papper, E. M. Experiences with General Anesthesia in Patients with Familial Dysautonomia. J.A.M.A. 170: 529 (1959).

2. Feliner, M. J. Manifestations of Familial Autonomic Dysautonomia. A.M.A. Arch. Dermat. 89: 190 (1964).

3. Riley, C. M.; Day, R. L.; Greeley, D. M.; \& Langrord, W. S. Central Autonomic Dysfunction with Defective Lacrimation: Report of Five Cases. Pediatrics 3: 468 (1949).

4. Smith, A. A. \& Dancis, J. Response to Intradermal Histamine in Familial Dysautonomia: A Diagnostic Test. J. Pediat. 63: 889 (1963).

5. Yatsu, F. \& Tussman, W. Familial Dysautonomia (Riley-Day Syndrome): Case Report with Postmortem Findings of a Patient at Age 31. A.M.A. Arch. Neurol. \& Psychiat. 10: 459 (1964).

6. Smith, A. A. \& Dancis, J. Familial Pheochromocytoma Presenting as Familial Dysautonomia. J. of Pediat. 65: 463 (1964).

7. Smith, A. A.; TAYLOR, T.; \& Wortis, S. B. Abnormal Catecholamine Metabolism in Familial Dysautonomia. New England J. Med. 268: 705 (1963).

8. Geltzer, A. I.; Gluck, L.; Talner, N. S.; \& Polesky, H. F. Familial Dysautonomia: Studies in a Newborn Infant. New England J. Med. 271: 436 (1964).

9. Frller, J.; Smith, A. A.; Stone, S.; \& Dancis, J. Respiratory Control in Familial Dysautonomia. J. Pediat. 66: 509 (1965).

10. SMith, A. A. \& Dancis, J. Exaggerated Response to Infused Norephinephrine in Familial Dysautonomia. New England J. Med. 270: 704 (1964).

11. LAXDAL, D. E.; KherA, S. A. K.; \& HAworth, D. H. Familial Dysautonomia (Riley-Day Syndrome): Report of Two Siblings and a Review of the Literature. Canad. M.A.J.
84: 828 (1961).

12. Linde, L. M. Diagnosis and Management of Dysautonomia. Pediatrics 18: 692 (1956).

13. Moloshok, R. E. \& Moseley, J. E. Familial Dysautonomia: Pulmonary Manifestations. Pediatrics 17:327 (1956).

14. Hutchison, J. H. \& Hamiton, W. Familial Dysautonomia in Two Siblings. Lancet 1: 1216 (1962).

15. Burn, J. H. \& RAND, M. J. Sympathetic Postganglionic Mechanism. Nature, London 184: 163 (1959).

16. -_- Sympathetic Postganglionic Cholinergic Fibres. Brit. J. Pharmacol. 15: 56 (1960).

17. Feldberg, W. \& Fleischauer, K. A New Experimental Approach to the Physiology and Pharmacology of the Brain. Brit. M. Bull. 21: 36 (1965).

18. Ingram, W. R. Central Autonomic Mechanisms. Handbook of Physiology, Vol. 2, Section 1: Neurophysiology. Washington: American Physiological Society (1960), pp. 951-78.

19. EADE, M. N. Paroxysmal Hypertension in Spinal Cord Injuries (Autonomic Hyperreflexia). New Zealand M. J. 63: 574 (1964).

20. French, J. D. The Reticular Formation. Handbook of Physiology, Vol. 2, Section I: Neurophysiology. Washington: American Physiological Society (1960), pp. 1281-1305.

21. Gilbert, Richard G. B. Personal communication. 